\title{
VOLUME, BIOMASSA E RENDIMENTO DE ÓLEOS ESSENCIAIS DO CRAVEIRO (Pimenta pseudocaryophyllus (GOMES) LANDRUM)
}

\author{
"Craveiro" (Pimenta pseudocaryophyllus (Gomes) Landrum) \\ Essential Oil Volume, Biomass and Yield
}

\author{
Eduardo Aguiar Girard \\ Eng. Agrônomo, Curso de Pós-graduação em Engenharia Florestal - Manejo Florestal, \\ UFPR, Curitiba - PR. e-mail: girard_eduardo@yahoo.com.br. \\ Henrique Soares Koehler \\ Universidade Federal do Paraná, Setor de Ciências Agrárias, Curitiba - PR. e-mail: koehler@ufpr.br.
}

\section{Sylvio Péllico Netto}

Professor Titular de Centro de Ciências Agrárias e Ambientais, da Pontifícia Universidade Católica do Paraná e Professor Sênior do Curso de Pós-Graduação da UFPR, Curitiba - PR. e-mail: pellico.sylvio@pucpr.br.

\begin{abstract}
Resumo
O objetivo deste trabalho foi ajustar equações de regressão lineares que expressem, para a espécie Pimenta pseudocaryophyllus (Gomes) Landrum, o volume total com casca, a biomassa aérea seca total e por compartimentos e determinar o rendimento de seu óleo essencial. Dentre os modelos testados para a obtenção das estimativas do volume com casca, o escolhido foi $v=b_{0}+b_{1} d^{2}+b_{2} d^{2} h+b_{3} h$, com um $\mathrm{R}^{2}$ de 0,90 e um $\mathrm{s}_{\mathrm{yx}}$ de 10,2\%. O modelo escolhido para as estimativas da biomassa seca aérea foi y $=\mathrm{h}\left(\mathrm{b}_{0}+\mathrm{b}_{1} \mathrm{~d}+\mathrm{b}_{2} \mathrm{~d}^{2}\right)$, com $\mathrm{R}^{2}=0,97 \mathrm{e} \mathrm{s}=8,2 \%$, e para biomassa seca de fuste $\mathrm{y}=\mathrm{b}_{0}+\mathrm{b}_{1} \mathrm{~h}+\mathrm{b}_{2} \mathrm{~d}^{2}+$ $\mathrm{b}_{3} \mathrm{~d}^{2} \mathrm{~h}$, com $\mathrm{R}^{2}=0,97$ e s $_{\mathrm{vx}}=7,9 \%$, Para biomassa seca de folhas e galhos vivos o modelo que apresentou melhores resultados foi $y=b_{0}+b_{1} d+b_{2} h+b_{3} d^{2}+b_{4} d^{2} h+b_{5} d h$ com um coeficiente de determinação de 0,95 e 0,99 , e erro-padrão da estimativa de $10,1 \%$ e 3,14 \%, respectivamente. A produção de biomassa aérea seca média foi de $21,96 \mathrm{~kg}$, sendo que $76 \%$ dessa biomassa está contida no fuste, $19 \%$ nos galhos vivos e $5 \%$ nas folhas. As estimativas por ha apresentaram $394,7 \mathrm{~kg} \mathrm{ha}^{-1}$ de biomassa aérea seca total e $15,2 \mathrm{~kg} \mathrm{ha}^{-1}$ de biomassa seca de folhas. O rendimento de óleo foi de $26,4 \mathrm{mg} \mathrm{g}^{-1}$, o que representa um rendimento de 2,64\%. O rendimento de óleo estimado por ha, a partir das estimativas de biomassa de folhas, foi de 402,4 $\mathrm{g} \mathrm{ha}^{-1} \mathrm{em}$ base seca. As estimativas individuais apresentaram, em média, 45,5 $\mathrm{kg}$ de biomassa aérea total seca, $1,8 \mathrm{~kg}$ de biomassa seca de folhas e um rendimento médio de óleo essencial de $46,4 \mathrm{~g}$ em base seca.
\end{abstract}

Palavras-chave: Pimenta pseudocaryophyllus; Funções volumétricas; Biomassa; Óleo essencial. 


\begin{abstract}
The main objective of the present study was to fit linear equations to estimate over bark volume, dry total and per compartments above ground biomass, as well as determine essential oil yield. Dendrometric data were taken at Tijucas do Sul, Parana State, in an area of mixed araucaria-hardwoods forest, belonging to the Pontifical Catholic University of Parana. Basic dendrometric data were composed of relative measures on 40 trees of the species. Data for dry biomass and essential oil yield determination came from six cut trees, representing the DBH classes found in the area. Biomass measurements for the different compartments were done by destructive method, with dry weights determined later at the laboratory. Among the fitted models for volume estimation, $v=b_{0}+b_{1} d^{2}+b_{2} d^{2} h+b_{3} h$, showed a determination coefficient of 0.90 and a standard error of $10.2 \%$. The model chosen for estimation of above ground dry biomass was $y=h\left(b_{0}+b_{1} d+b_{2} d^{2}\right)$ with $R^{2}=0.97$ e $s_{y x}=8.2 \%$. For bark dry biomass estimation the chosen model was $y=b_{0}+b_{1} h+b_{2} d^{2}+b_{3} d^{2} h$, showing $R^{2}=0.97$ e $s_{y x}=7.9 \%$. Dry branches and dry leaves biomass were estimated by the equation $y=b_{0}+b_{1} d+b_{2} h+b_{3} d^{2}+b_{4} d^{2} h+b_{5} d h$, which showed 0.95 and 0.99 as coefficient of determination and $10.1 \% 3.14 \%$ as standard error, respectively. Dry biomass production for the cut trees was $21.96 \mathrm{~kg}$, being $76 \%$ of the dry biomass belonging to the stem, $19 \%$ to the branches and 5\% to the leaves. The estimates by hectare were $394.7 \mathrm{~kg} \mathrm{ha}^{-1}$ of dry biomass above ground and $15.2 \mathrm{~kg} \mathrm{ha}^{-1}$ of dry leaves. Oil production yield for the cut trees was $26.4 \mathrm{mg} \mathrm{g}^{-1}(\mathrm{D} / \mathrm{W})$, which represents $2.64 \%(w / w \% D W)$. The essential oil yield from leaves estimated by hectare was $402.4 \mathrm{~g} \mathrm{ha}{ }^{-1}$. Individual estimations showed, on average, $45.5 \mathrm{~kg}$ of total dry biomass above ground, $1.8 \mathrm{~kg}$ of dry biomass of leaves and for essential oil yield, an average of $46.4 \mathrm{~g}(\mathrm{~d} / \mathrm{w})$.
\end{abstract}

Keywords: Pimenta pseudocaryphyllus; Volume functions; Biomass, Essential oil.

\title{
INTRODUÇÃO
}

A existência de extensas áreas florestais no Estado do Paraná foi ponto fundamental para uma colonização abrangente e para o exercício do desenvolvimento da atividade florestal extrativista. As florestas começaram a ser derrubadas aproximadamente em 1895, quando o Estado do Paraná dispunha de uma área de florestas primitivas em torno de $167.824 \mathrm{~km}^{2}$, sendo que cerca de $73.780 \mathrm{~km}^{2}$ eram compostas de floresta natural de pinheiro (MAACK, 1968).

Dentre as espécies presentes nas florestais remanescentes, existem espécies que possuem óleos essenciais cujo aproveitamento é explorado desde muito, destacando-se entre elas o craveiro (Pimenta pseudocaryophyllus (Gomes) Landrum) da família das Myrtaceae.

Existe um desconhecimento da composição química de óleos essenciais não só das mirtáceas, como também de toda flora brasileira, tão rica no que se refere aos metabólicos secundários. Gottlieb e Mors (1980) citam que cerca de 99,6\% de nossa flora é quimicamente desconhecida. O óleo essencial contém inúmeras substâncias cuja atividade biológica recentemente tem sido objeto de investigações.

O óleo essencial obtido do craveiro (Pimenta pseudocaryophyllus (Gomes) Landrum) possui inúmeras aplicações, desde o uso em aromatizantes, perfumes, cosméticos e inseticidas até na indústria fármaco-medicinal, dada suas propriedades antibacterianas, analgésicas e sedativas.

A extração do óleo de folhas de craveiro é discutida neste estudo como alternativa, que pode ser viabilizada por meio de manejo florestal apropriado, sem sacrificar as árvores nativas, que poderiam ser cultivadas e melhoradas.

Considerando a carência de informações sobre essa espécie, este trabalho teve como objetivo testar modelos matemáticos, selecionando os de melhor ajuste e acuidade; que expressem relação com variáveis dendrométricas de fácil obtenção, para estimar: 
- o volume comercial do craveiro $\left(\mathrm{m}^{3}\right)$;

- a biomassa seca total e por compartimentos do craveiro (kg);

- a produtividade de óleo essencial a partir das folhas $\left(\mathrm{ml} \mathrm{ha}^{-1}\right)$.

\section{MATERIAL E MÉTODOS}

\section{Estimativas volumétricas}

Foram amostradas 40 árvores na área, as quais foram cubadas em pé com o auxílio de uma escada, segundo a metodologia de cubagem proposta por Smalian, tomando medidas de circunferências a alturas relativas ao longo do fuste, até o ponto de inversão morfológica da árvore. A marcação dos pontos de medição foi realizada em 14 posições relativas à altura comercial da árvore, sendo elas $0,0 \%, 1,0 \%, 5 \%$, $10 \%, 15 \%, 25 \%, 35 \%, 45 \%, 55 \%, 65 \%, 75 \%, 85 \%, 95 \%$ e $100 \%$ dessa altura, bem como foi marcada a posição a 1,30 metros (CAP). Os volumes foram calculados pela fórmula de Smalian. Os modelos testados foram os seguintes:

$\begin{array}{ll}\text { Meyer } & \mathrm{v}=\mathrm{b}_{0}+\mathrm{b}_{1} \mathrm{~d}+\mathrm{b}_{2} \mathrm{~d}^{2}+\mathrm{b}_{3} \mathrm{dh}+\mathrm{b}_{4} \mathrm{~d}^{2} \mathrm{~h}+\mathrm{b}_{5} \mathrm{~h} \\ \text { Stoate } & \mathrm{v}=\mathrm{b}_{0}+\mathrm{b}_{1} \mathrm{~d}^{2}+\mathrm{b}_{2} \mathrm{~d}^{2} \mathrm{~h}+\mathrm{b}_{3} \mathrm{~h} \\ \text { Schumacher } & \log \mathrm{v}=\mathrm{b}_{0}+\mathrm{b}_{1} \log \mathrm{d}+\mathrm{b}_{2} \log \mathrm{h} \\ \text { Spurr } & \mathrm{v}=\mathrm{b}_{0}+\mathrm{b}_{1} \mathrm{~d}^{2} \mathrm{~h} \\ \text { Péllico } & \mathrm{v}=\mathrm{h}\left(\mathrm{b}_{0}+\mathrm{b}_{1} \mathrm{~d}+\mathrm{b}_{2} \mathrm{~d}^{2}\right) \\ \text { Husch } & \log \mathrm{v}=\mathrm{b}_{0}+\mathrm{b}_{1} \log \mathrm{d} \\ \text { Spurr } & \log \mathrm{v}=\mathrm{b}_{0}+\mathrm{b}_{1} \log \left(\mathrm{d}^{2} \mathrm{~h}\right) \\ \text { Hohenadl } & \mathrm{v}=\mathrm{b}_{0}+\mathrm{b}_{1} \mathrm{~d}+\mathrm{b}_{2} \mathrm{~d}^{2}\end{array}$

onde:

$\mathrm{v}=$ volume com casca $\mathrm{em}^{3}$;

$\mathrm{d}=$ diâmetro a 1,30 metros do solo, em cm;

$\mathrm{h}=$ altura comercial $\mathrm{em} \mathrm{m}$.

\section{Quantificação da biomassa}

A quantificação da biomassa verde do craveiro, aqui entendida como a porção acima do solo, foi realizada usando-se o método destrutivo, onde o indivíduo é abatido e seus componentes separados nos diferentes compartimentos, considerando cada árvore como uma unidade de amostra. Foram selecionadas seis (6) árvores de craveiro, uma em cada classe de diâmetro das árvores encontradas na área em estudo. O número de árvores abatidas foi limitado, pois existem restrições de abate que visam a minimizar os danos causados na floresta, sob o ponto de vista ecológico e ambiental.

Cada uma das árvores abatidas foi cortada e separada em porções referentes aos galhos vivos, folhas, fuste com casca e a porção denominada miscelânea (material que não se enquadrava em nenhuma das classes anteriores). Os componentes maiores da biomassa, após serem separados em porções menores, foram pesados no campo com balança de braço tipo pescador, com capacidade para pesar até $15 \mathrm{~kg}$ e com precisão de 100 gramas.

Para a determinação do teor de umidade de cada componente procedeu-se de modo diferenciado. Na porção relativa ao fuste, que compreende a madeira e a casca, foram retirados três discos do tronco da árvore, o primeiro na base, o segundo no meio e o terceiro na ponta, abaixo do ponto de inversão morfológica (altura comercial). 
A determinação da biomassa verde dos galhos vivos, folhas e miscelânea foi feita separandose e pesando-se cada porção.

Os diferentes tipos de amostras coletadas, que contemplam o tronco com casca, os galhos vivos e as folhas foram acondicionados em sacos de papel, identificados e enviados ao Laboratório de Solos da Pontifícia Universidade Católica do Paraná. Em laboratório, essas amostras foram secas em estufa de renovação e circulação de ar, a uma temperatura constante de $75^{\circ} \mathrm{C}$ até atingir o peso constante, para posterior determinação dos pesos secos.

Com base nos dados relativos à biomassa verde e teores de umidade, para cada componente amostrado nas árvores abatidas, foram calculadas as quantidades de biomassa seca, pelo uso da seguinte fórmula:

$\mathrm{bs}=\mathrm{bv} \cdot(1-\mathrm{u})$

onde:

bs = biomassa seca $(\mathrm{kg})$;

$\mathrm{bv}=$ biomassa verde $(\mathrm{kg})$;

$\mathrm{u}=$ teor de umidade $(\%)$.

\section{Equações de biomassa testadas}

Tendo obtido os pesos em kg, de cada um dos componentes das seis (6) árvores abatidas, para determinação da biomassa verde e posterior transformação em biomassa seca, e de posse dos dados dendrométricos obtidos durante a cubagem das mesmas árvores, foram ajustados modelos lineares simples e múltiplas para a obtenção das estimativas das quantidades de biomassa seca para o craveiro.

Os modelos testados foram os seguintes:

$$
\begin{aligned}
& \text { ps }=b_{0}+b_{1} d \\
& \text { ps }=b_{0}+b_{1} d+b_{2} h \\
& \text { ps }=b_{0}+b_{1} d+b_{2} h+b_{3} d^{2}+b_{4} d^{2} h+b_{5} d h \\
& \text { ps }=b_{0}+b_{1} d^{2} h \\
& \text { ps }=b_{0}+b_{1} h+b_{2} d^{2}+b_{3} d^{2} h \\
& \text { ps }=h\left(b_{0}+b_{1} d+b_{2} d^{2}\right)
\end{aligned}
$$

onde:

ps = peso seco em $\mathrm{kg}$;

$\mathrm{d}=$ diâmetro à altura do peito em $\mathrm{cm}$;

$\mathrm{h}=$ altura comercial em $\mathrm{m}$;

$\mathrm{b}_{0}, \mathrm{~b}_{1}, \ldots, \mathrm{b}_{\mathrm{n}}=$ coeficientes estimados.

A seleção das melhores equações foi feita considerando-se as estatísticas Coeficiente de Determinação $\left(\mathrm{R}^{2}\right)$, Erro-Padrão da Estimativa $\left(\mathrm{s}_{\mathrm{xy}}\right)$ e Somatório dos Resíduos.

\section{Extração do óleo essencial}

Para as seis (6) árvores abatidas, representativas de todas as classes diamétricas existentes na área, foi determinada a fitomassa total de folhas de cada árvore e a partir delas foram retiradas amostras e encaminhadas para o laboratório de Engenharia de Alimentos da Pontifícia Universidade Católica do Paraná. 
As folhas foram coletadas com o auxílio de uma tesoura de poda, em quatro pontos distintos da copa das árvores e, após, misturadas, formando amostras compostas, acondicionadas em sacos de papel, identificadas e levadas para o laboratório de extração de óleo essencial.

Depois de cortadas, foram pesadas 200 gramas de folhas para que se determinasse a quantidade de água a ser utilizada na extração. Para o processo de extração, foi utilizada água deionizada, em proporção de três vezes o peso da amostra.

O processo de extração de óleo utilizado foi o de destilação por arraste de vapor de água, num sistema de Clevenger, onde as folhas foram colocadas no balão de extração volumétrico, que foi aquecido até $80^{\circ} \mathrm{C}$.

O rendimento foi calculado para a relação massa do óleo, medida por sua densidade a partir do volume de óleo obtido no sistema de extração, dividido pela massa seca da amostra. O rendimento de óleo obtido de cada amostra foi então calculado pela fórmula:

$$
R \%=\frac{\text { volume }_{\text {oleo }} \cdot \text { densidade }}{\text { massa }_{a}} \cdot 100
$$

onde:

$\mathrm{R} \%=$ rendimento em porcentagem;

volume $_{\text {óleo }}=$ volume de óleo em ml;

densidade = massa de um $\mathrm{ml}$ de óleo em g;

massa $_{\mathrm{a}}=$ massa seca de folhas em $\mathrm{g}$.

Para a realização do procedimento de extração, foram utilizados como líquido de arraste água deionizada, e o conjunto extrator tipo Clevenger, que é composto de balão de destilação de $1000 \mathrm{ml}$, condensador de bolas e manta de aquecimento.

Foi observado que à medida que o volume de óleo aumentava na superfície do aparelho de Clevenger, pequenas gotículas retornavam ao balão de destilação e, quando o volume de óleo na superfície do aparelho aumentava consideravelmente, havia o retorno dele em forma de gotas para o balão de destilação. Isto foi devido à densidade do óleo essencial ser muito próximo à da água e, também, o vencimento da tensão superficial do aparelho de Clevenger, resultando, assim, um menor rendimento na extração do óleo essencial. Para evitar a perda de rendimento, foi necessário retirar o óleo toda vez que atingisse volume predefinido e, assim, foi possível obter um maior rendimento na extração do óleo, o que também foi observado por Lullez (1991).

\section{Estimativa da produção de óleo}

A partir dos dados de três amostras de um hectare cada, integrantes da rede de parcelas permanentes do Projeto Ecológico de Longa Duração (PELD), localizadas no Vivat Floresta Park, em Tijucas do Sul, Paraná, pertencentes à Pontifícia Universidade Católica do Paraná, a quantidade de biomassa verde das folhas das árvores de craveiro (Pimenta pseudocaryophyllus) presentes em cada amostra foi estimada por meio da equação biomassa de folhas estimada. A altura comercial das árvores foi estimada pela função:

onde:

$$
\mathrm{hc}=\mathrm{b}_{0} \mathrm{~d}_{1}
$$

hc $=$ altura comercial em m;

$\mathrm{d}=$ diâmetro à altura do peito em $\mathrm{cm}$;

$\mathrm{b}_{0}, \mathrm{~b}_{1}=$ coeficientes da equação. 
O total de óleo essencial de cada amostra foi obtido pela soma das quantidades individuais estimadas, tendo sido também estimada a média e o intervalo de confiança da quantidade de óleo essencial por árvore:

$$
I C=\left[\bar{x}-\left(t_{\alpha} \cdot s_{\bar{x}}\right) \leq \mu \leq \bar{x}+\left(t_{\alpha} \cdot s_{\bar{x}}\right)\right]=1-\alpha
$$

onde:

IC = intervalo de confiança;

= estimativa da média;

$\mathrm{t}_{\mathrm{a}}=$ valor tabelado a $5 \%$ de probabilidade;

$\mathrm{s}_{\overline{\mathrm{x}}}^{\mathrm{a}}=$ erro-padrão;

$\mathrm{m}=$ média paramétrica;

$\mathrm{a}=$ nível de probabilidade $(5 \%)$.

\section{RESULTADOS E DISCUSSÃO}

\section{Equações volumétricas}

Os resultados dos ajustes dos modelos de equações que exprimem o volume comercial individual do craveiro (Pimenta pseudocaryophyllus), em $\mathrm{m}^{3}$, em função do diâmetro a altura do peito e da altura comercial estão apresentados no Quadro 1.

Os resultados obtidos mostraram que as EQUAÇÕES 1 (Meyer), 2 (Stoate) e 3 (Schumacher-

QUADRO 1 - Resultados do ajuste das equações que estimam os volumes comerciais com casca, em $\mathrm{m}^{3}$, em função do diâmetro a altura do peito e da altura comercial e respectivas estatísticas $\mathrm{F}, \mathrm{R}^{2}$ e $\mathrm{s}_{\mathrm{yx}} \%$ Chart 1 - Results of the equations adjustment that estimate the commercial volumes with bark, in $\mathrm{m}^{3}$, function of the $D B H$ and of the commercial height, with the respective statistics (F, $\mathrm{R}^{2}$ and $\left.s_{y x} \%\right)$

\begin{tabular}{lrrr}
\hline EQUACĀO & $\mathrm{F}$ & $\mathrm{R}^{2} \mathrm{~s}_{\mathrm{yx}} \%$ \\
\hline $\begin{array}{r}1-\mathrm{v}=0,000096-0,001637 \mathrm{~d}-0,005883 \mathrm{~h}+0,000307 \mathrm{~d}^{2}-0,000105 \mathrm{~d}^{2} \mathrm{~h} \\
\quad+0,001983 \mathrm{dh}\end{array}$ & 84,45 & 0,91 & 9,9 \\
$2-\mathrm{v}=-0,000059+0,000512 \mathrm{~d}^{2}+0,000121 \mathrm{~d}^{2} \mathrm{~h}+0,000038 \mathrm{~h}$ & 125,54 & 0,90 & 10,2 \\
$3-\log \mathrm{v}=-8,703208+1,891482 \log \mathrm{d}+0,597721 \log \mathrm{h}$ & 139,12 & 0,88 & 10,5 \\
$4-\mathrm{v}=0,003449+0,000064 \mathrm{~d}^{2} \mathrm{~h}$ & 218,81 & 0,84 & 12,9 \\
$5-\mathrm{v}=\mathrm{h}\left(-0,00114+0,0000028 \mathrm{~d}+0,000081 \mathrm{~d}^{2}\right)$ & 100,43 & $0,8316,3$ \\
$6-\log \mathrm{v}=-7,206412+1,549400 \log \mathrm{d}$ & 74,29 & $0,6518,8$ \\
$7-\log \mathrm{v}=-4,751421+0,003089 \log \left(\mathrm{d}^{2} \mathrm{~h}\right)$ & 122,33 & 0,76 & 16,1 \\
$8-\mathrm{v}=-0,000451+0,001369 \mathrm{~d}+0,000132 \mathrm{~d}^{2}$ & 52,66 & 0,72 & 17,8 \\
\hline
\end{tabular}


Hall) apresentaram os melhores coeficientes de determinação, bem como os menores erros-padrão da estimativa em porcentagem. As diferenças encontradas nos valores do coeficiente de determinação e erro padrão da estimativa em porcentagem são desprezíveis do ponto de vista estatístico, apresentando valores aceitáveis do ponto de vista florestal, levando-se em conta tratar-se da estimativa de volume de uma espécie que ocorre em florestas naturais.

A distribuição dos resíduos dos modelos 1 (Meyer) e 2 (Stoate) pode ser observada nas Figuras 1 e 2. Pela análise gráfica das distribuições, verifica-se que os dois melhores modelos não apresentam diferenças marcantes quanto sua dispersão, permitindo dessa forma escolher o modelo 2 (Stoate) como o mais apropriado, visto que esse modelo é mais simples do que o modelo 1 (Meyer), com estatísticas iguais do ponto de vista prático.

Como exemplo de ajuste de equações de volume, Paton (1984), dentre treze modelos testados

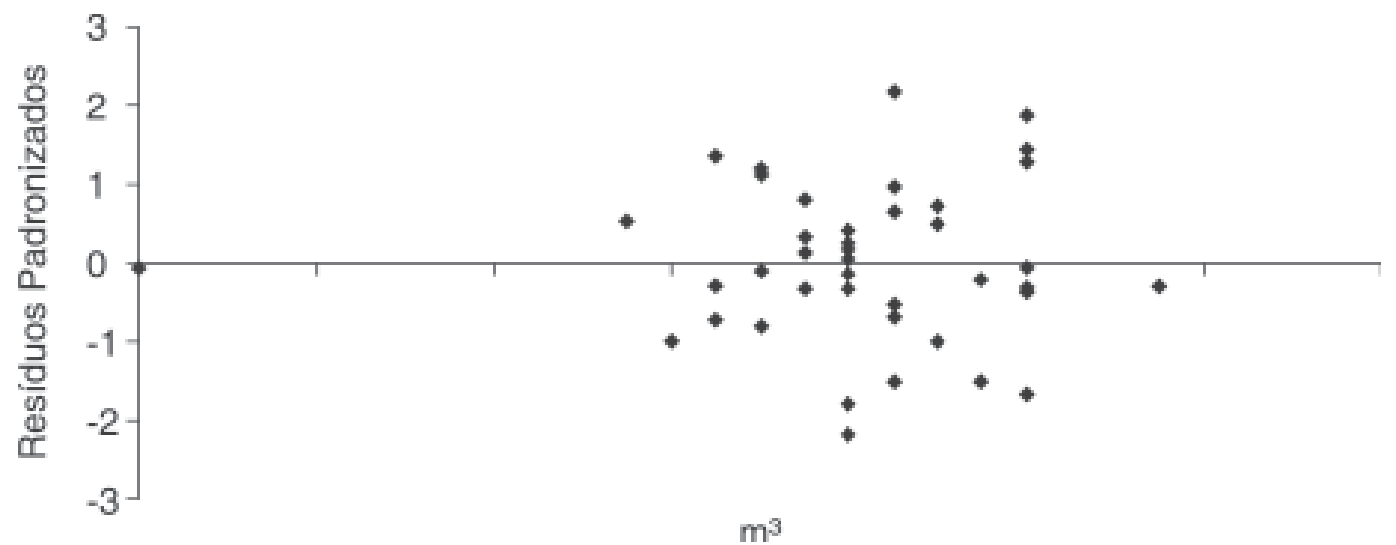

FIGURA 1 - Distribuição dos resíduos padronizados para o modelo 1 (Meyer)

Figure 1 - Distribution of the standardized residues for model 1 (Meyer)

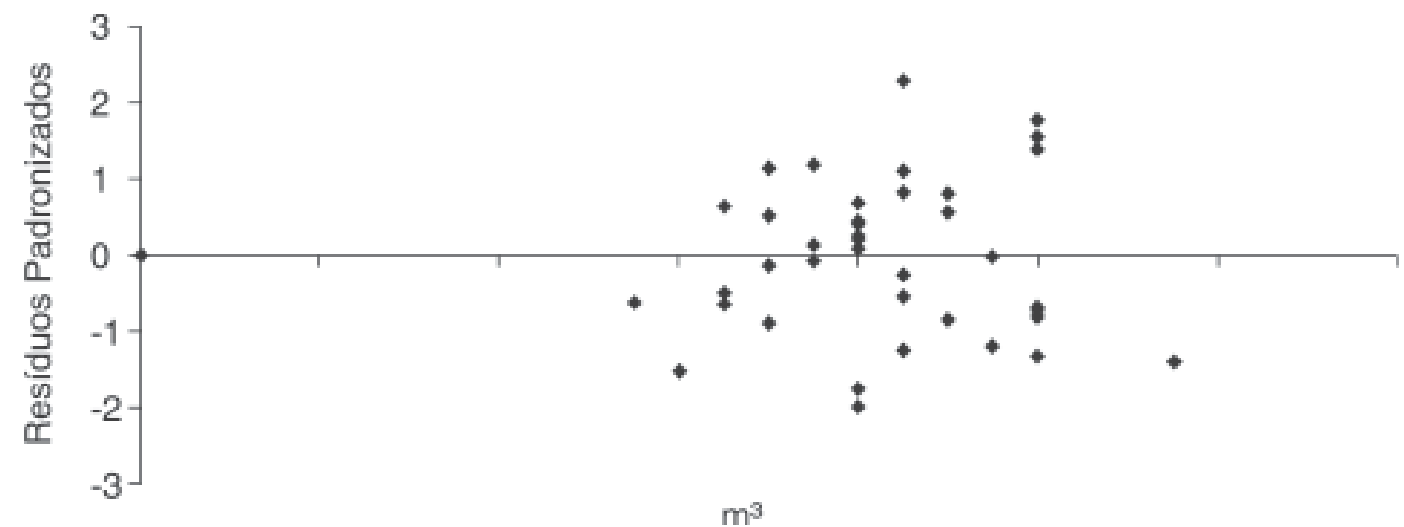

FIGURA 2 - Distribuição dos resíduos padronizados para o modelo 2 (Stoate)

Figure 2 - Distribution of the standardized residues for model 2 (Stoate) 
para a confecção da tabelas de volume comercial com casca para a bracatinga (Mimosa scabrella Benth), escolheu a equação logarítmica de SPURR:

$$
\log \mathrm{v}=-4,48820703+1,044443097 \log \mathrm{d}^{2} \mathrm{~h}
$$

Esta equação apresentou coeficiente de correlação múltipla de 0,99 , erro-padrão da estimativa $\mathrm{s}_{\mathrm{yx}}=0,044$ e erro-padrão da estimativa em porcentagem de $16,01 \%$, como a de melhor ajuste, seguida pela equação de Schumacher e Hall.

\section{Equações de biomassa aérea}

Os resultados dos ajustes dos modelos de equações que exprimem a biomassa aérea seca do craveiro, entendida como aquela acima do solo, em kg, em função do diâmetro à altura do peito e da altura comercial estão apresentados no Quadro 2.

QUADRO 2 - Resultados do ajuste das equações que estimam a biomassa aérea seca, em kg, em função do diâmetro à altura do peito e da altura comercial e respectivas estatísticas $\mathrm{F}, \mathrm{R}^{2}$ e s ${ }_{\mathrm{yx}} \%$

Chart 2 - Results of the equations adjustment that estimate the dry aboveground biomass, in $\mathrm{kg}$, function of the DBH and of the commercial height, with the respective statistics (F, $\mathrm{R}^{2}$ and $\left.s_{y x} \%\right)$

\begin{tabular}{|c|c|c|c|}
\hline EQUAÇĀO & $\mathrm{F}$ & $\mathrm{R}^{2}$ & $\overline{s_{y x} \%}$ \\
\hline $1-y=5,092633+1,830661 d$ & 8,48 & 0,55 & 30,2 \\
\hline $2-y=3,423637+0,994122 d+2,130317 h$ & 5,29 & 0,58 & 29,0 \\
\hline $\begin{aligned} 3-y= & 0,003297+1,730917 d+6,253799 h+0,165655 d^{2}-0,03107\left(d^{2} h\right) \\
& -0,60033(d h)\end{aligned}$ & 31,25 & 0,96 & 8,9 \\
\hline $4-y=13,15335+0,019166\left(d^{2} h\right)$ & 1,36 & 0,06 & 44,0 \\
\hline $5-y=0,08562+5,147161 h+0,364603 d^{2}-0,08531\left(d^{2} h\right)$ & 123,61 & 0,98 & 5,7 \\
\hline $6-y=h\left(0,077154+5,875792 d-0,37259 d^{2}\right)$ & 88,13 & 0,97 & 8,2 \\
\hline
\end{tabular}

Os menores erros-padrão da estimativa em porcentagem foram os das equações 5 (Stoate) e 6 (Péllico). As diferenças encontradas nos valores dos erros-padrão da estimativa desses modelos são pequenas e desprezíveis do ponto de vista estatístico e florestal. O modelo 6 (Péllico) apresenta um coeficiente de determinação igual ao modelo 5 (Stoate), porém, mesmo apresentando um erro-padrão da estimativa maior, é um modelo mais simples, o que é sempre desejável. Os resíduos padronizados do modelo estão apresentados na Figura 3. 


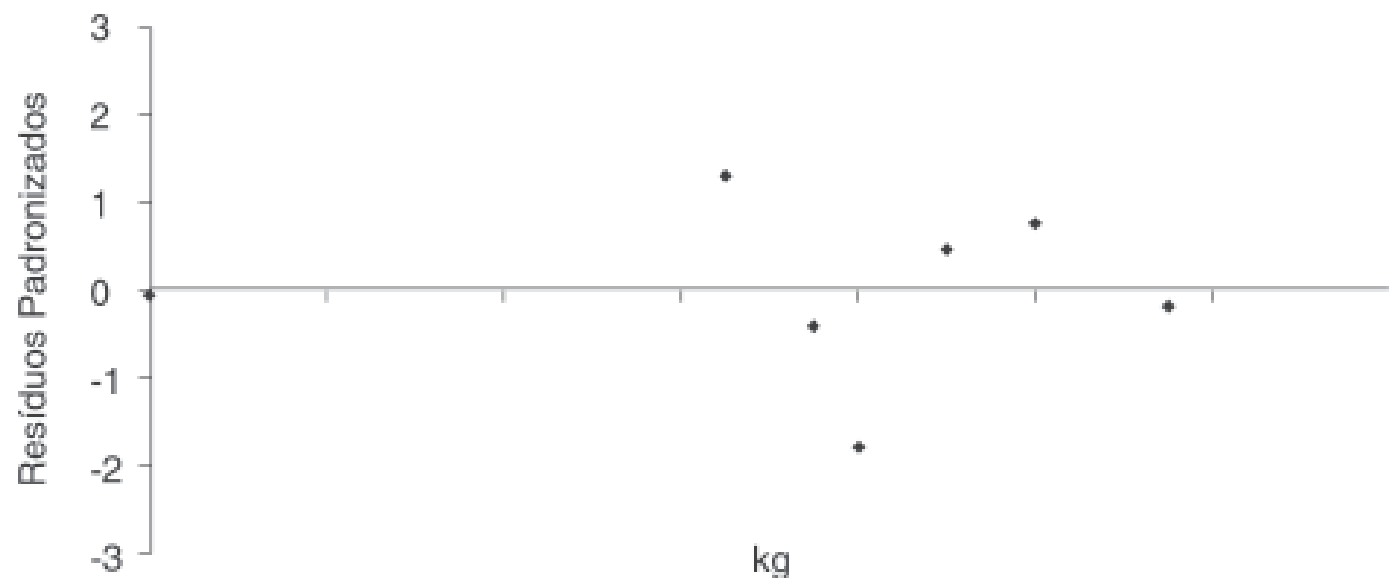

FIGURA 3 - Distribuição dos resíduos padronizados para o modelo 5 de (Péllico)

Figure 3 - Distribution of the standardized residues for model 5 (Pellico)

Watzlawick (2003) estimou a biomassa arbórea de uma Floresta Ombrófila Mista Montana em função de respostas espectrais das diferentes bandas e índices de vegetação das imagens de satélite, encontrando para o melhor modelo um coeficiente de determinação de 0,71 e um erro-padrão da estimativa de $30,87 \%$.

\section{Equações de biomassa do fuste}

Os resultados dos ajustes dos modelos de equações que exprimem a biomassa do fuste do craveiro, em kg, em função do diâmetro à altura do peito e da altura comercial são apresentados no Quadro 3.

Os modelos 5 (Stoate), 3 (Meyer) e 6 (Péllico) apresentaram os melhores coeficientes de determinação e erro-padrão da estimativa em porcentagem. O melhor modelo foi o 5 (Stoate) com 0,97 de coeficiente de determinação para um erro-padrão da estimativa de 7,9\%. As distribuições dos resíduos padronizados para o melhor modelo estão apresentados na Figura 4.

O melhor modelo para a estimativa do peso da matéria seca do fuste obtido por SOCHER (2004)

QUADRO 3 - Resultados do ajuste das equações que estimam a biomassa seca do fuste, em $\mathrm{kg}$, em função do diâmetro à altura do peito e da altura comercial e respectivas estatísticas $\mathrm{F}, \mathrm{R}^{2}$ e $\mathrm{s}_{\mathrm{yx}} \%$

Chart 3 - Results of the equations adjustment that estimate the dry biomass of the bole, in $\mathrm{kg}$, function of the DBH and of the commercial height, with the respective statistics ( $F, \mathrm{R}^{2}$ and $\left.s_{y x} \%\right)$

\begin{tabular}{lrrr}
\hline EQUAÇ̄O & F & $R^{2} s_{y x} \%$ \\
\hline $1-y=3,800501+1,39986 d$ & 8,48 & 0,55 & 30,4 \\
$2-y=2,559296+0,77774 d+1,584282 h$ & 5,16 & 0,58 & 29,5 \\
$3-y=0,002882-0,15163 d+8,038167 h+0,320486 d^{2}-0,02016\left(d^{2} h\right)-$ & 23,86 & 0,95 & 10,2 \\
$0,93215(d h)$ & 1,40 & 0,06 & 44,1 \\
$4-y=9,919864+0,014806\left(d^{2} h\right)$ & 65,47 & 0,97 & 7,9 \\
$5-y=0,002348+3,881021 h+0,281033 d^{2}-0,06516\left(d^{2} h\right)$ & 40,36 & 0,93 & 12,1 \\
$6-y=h\left(0,106232+4,379396 d-0,27444 d^{2}\right)$ & &
\end{tabular}




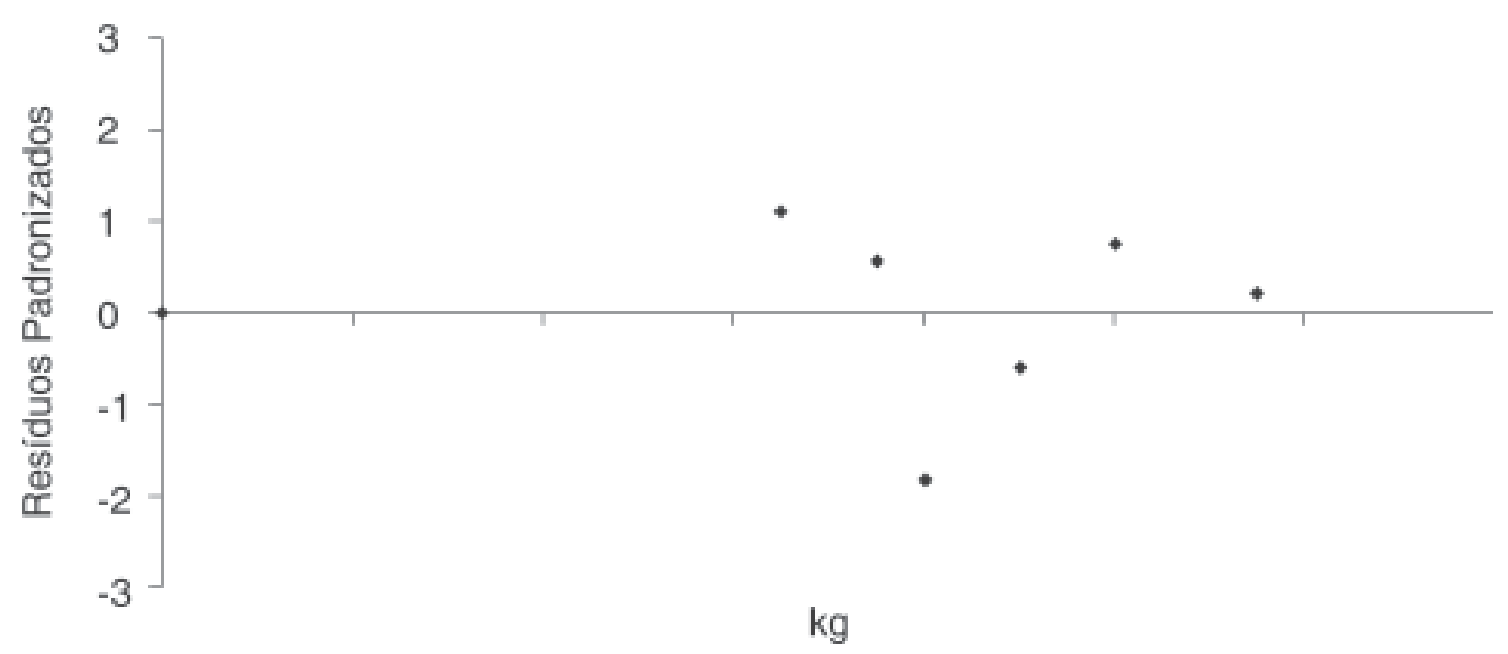

FIGURA 4 - Distribuição dos resíduos padronizados para o modelo 5 de (Stoate) Figure 4 - Distribution of the standardized residues for model 5 (Stoate)

apresentou um coeficiente de determinação ajustado de 0,94 para um erro-padrão da estimativa de 20,21\%.

\section{Equações de biomassa das folhas}

Os resultados dos ajustes dos modelos de equações que exprimem a biomassa das folhas do craveiro, em kg, em função do diâmetro à altura do peito e da altura comercial são apresentados no Quadro 4.

O modelo 3 (Meyer), que relaciona a biomassa das folhas de craveiro em função do diâmetro

QUADRO 4 - Resultados do ajuste das equações que estimam a biomassa seca das folhas, em $\mathrm{kg}$, em função do diâmetro a altura do peito e da altura comercial e respectivas estatísticas $\mathrm{F}, \mathrm{R}^{2}$ e $\mathrm{s}_{\mathrm{yx}} \%$ Chart 4 - Results of the equations adjustment that estimate the dry biomass of leaves, in $\mathrm{kg}$, function of the DBH and the commercial height, with the respective statistics $\left(F, R^{2}\right.$ and $\left.s_{y x} \%\right)$

\begin{tabular}{|c|c|c|c|}
\hline EQUAC̄̄̄O & $\mathrm{F}$ & $\mathrm{R}^{2}$ & $s_{y x} \%$ \\
\hline $1-y=0,256002+0,094084 d$ & 8,80 & 0,56 & 29,8 \\
\hline $2-y=0,130481+0,03117 d+0,160216 h$ & 11,12 & 0,77 & 21,6 \\
\hline $\begin{aligned} 3-y= & 0,000193+0,361624 d+0,360391 h=0,03018 d^{2}+0,006867\left(d^{2} h\right) \\
& -0,09442(d h)\end{aligned}$ & 23,68 & 0,95 & 10,1 \\
\hline $4-y=0,616273+0,001168\left(d^{2} h\right)$ & 2,20 & 0,17 & 41,3 \\
\hline $5-y=0,017182+0,263115 \mathrm{~h}+0,012081 \mathrm{~d}^{2}-0,0029\left(\mathrm{~d}^{2} \mathrm{~h}\right)$ & 30,62 & 0,93 & 11,4 \\
\hline $6-\mathrm{y}=\mathrm{h}\left(0,017406+0,28652 \mathrm{~d}-0,01772 \mathrm{~d}^{2}\right)$ & 31,56 & 0,91 & 13,5 \\
\hline
\end{tabular}


à altura do peito e da altura comercial, foi o modelo que apresentou os melhores resultados para o coeficiente de determinação $(0,95)$ e para o erro-padrão da estimativa $(10,1 \%)$. A distribuição dos resíduos para esse modelo é apresentada na Figura 5.

Socher (2004) obteve um ajuste dos modelos que estimam o peso de matéria seca das folhas

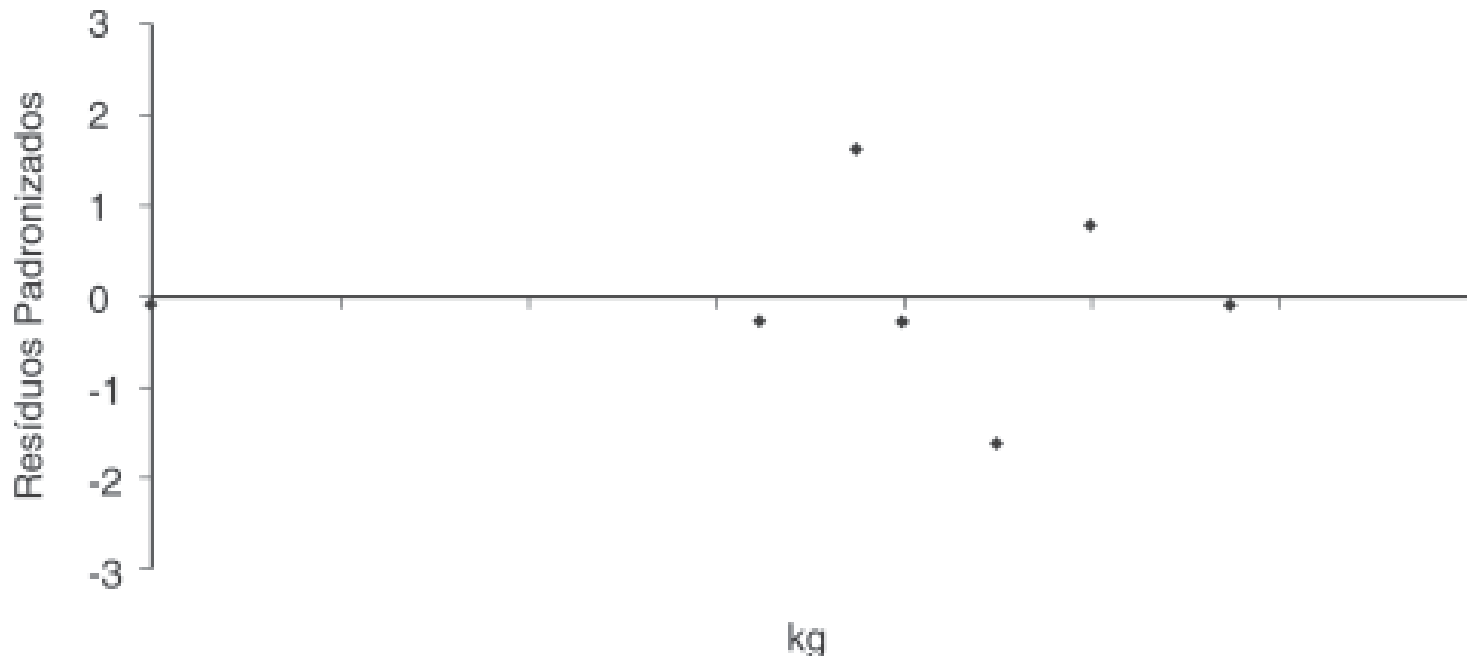

FIGURA 5 - Distribuição dos resíduos padronizados para o modelo 3 (Meyer)

Figure 5 - Distribution of the standardized residues for model 3 (Meyer)

com um coeficiente de determinação de 0,71 e um erro-padrão da estimativa de $62,8 \%$.

As estatísticas encontradas para o modelo 3 (Meyer) foram superiores às reportadas por Socher (2004), tanto a respeito ao ajuste do modelo quanto ao erro-padrão da estimativa em porcentagem.

\section{Equações de biomassa dos galhos vivos}

Os resultados dos ajustes dos modelos de equações que exprimem a biomassa dos galhos vivos do craveiro, em kg, em função do diâmetro à altura do peito e da altura comercial são apresentados no Quadro 5.

Os modelos 3 (Meyer) e 6 (Péllico) foram os que apresentaram os melhores resultados de ajuste. 
QUADRO 5 - Resultados do ajuste das equações que estimam a biomassa seca dos galhos vivos, em $\mathrm{kg}$, em função do diâmetro a altura do peito e da altura comercial e respectivas estatísticas $\mathrm{F}, \mathrm{R}^{2}$ e $\mathrm{s}_{\mathrm{vx}} \%$ Chart 5 - Results of the equations adjustment that estimate the dry biomass of the alive branches, in $\mathrm{kg}$, function of the $D B H$ and the commercial height, with the respective statistics (F, $\mathrm{R}^{2}$ and $\left.s_{y x} \%\right)$

\begin{tabular}{|c|c|c|c|}
\hline EQUAÇĀO & $\mathrm{F}$ & $\mathrm{R}^{2}$ & $\mathrm{~s}_{\mathrm{yx}} \%$ \\
\hline $1-y=1,036129+0,336717 d$ & 6,12 & 0,46 & 34,6 \\
\hline $2-y=0,73386+0,185212 d+0,385818 h$ & 3,44 & 0,45 & 34,9 \\
\hline $\begin{aligned} 3-y= & 0,000222+1,520921 d-2,14476 h-0,12465 d^{2}=0,01777\left(d^{2} h\right) \\
& +0,426239(d h)\end{aligned}$ & 268,66 & 0,99 & 3,14 \\
\hline $4-y=2,617217+0,003192\left(d^{2} h\right)$ & 0,91 & 0.01 & 47,5 \\
\hline $5-y=0,06609+1,003025 h+0,07149 d^{2}=0,01725\left(d^{2} h\right)$ & 11,50 & 0,84 & 18,8 \\
\hline $6-y=h\left(-0,04648+1,209876 d-0,08043 d^{2}\right)$ & 65,52 & 0,95 & 9,9 \\
\hline
\end{tabular}

Os coeficientes de determinação foram de 0,99 e 0,95 e os erros-padrão da estimativa foram 3,14\% e 9,9\%, respectivamente. A distribuição dos resíduos padronizados do modelo está apresentado na Figura 6.

Pela análise dos coeficientes de determinação, dos erros-padrão da estimativa e da distribuição dos resíduos padronizados, conclui-se que o modelo 3 (Meyer) foi o que apresentou o melhor ajuste.

Socher (2004), no ajuste dos modelos que estimam o peso de matéria seca dos galhos vivos, encontrou resultados inferiores ao modelo selecionado, com um coeficiente de determinação de 0,79 e um erro-padrão da estimativa de 53,91\%.

\section{Estimativas da biomassa aérea}

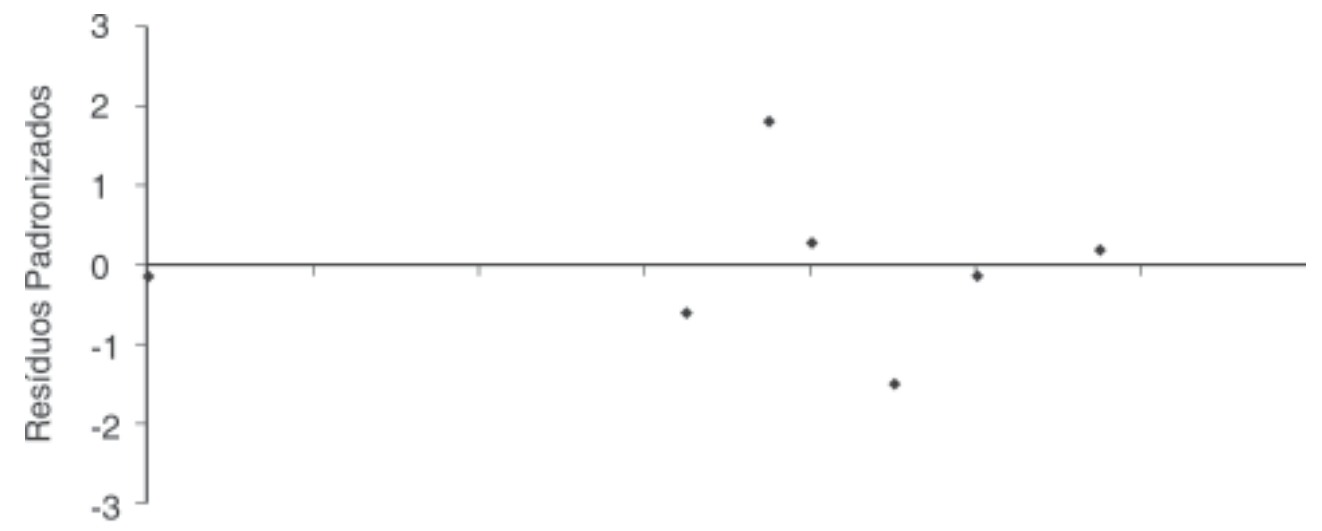

$\mathrm{kg}$

FIGURA 6 - Distribuição dos resíduos padronizados para o modelo 3 (Meyer) Figure 6 - Distribution of the standardized residues for model 3 (Meyer) 
As estimativas da biomassa aérea seca do fuste, dos galhos vivos e das folhas, determinadas pelo método destrutivo para as seis árvores amostradas, apresentaram os resultados mostrados na Tabela 1 e Figura 7.

O fuste (casca e madeira) apresentou 16,68 kg de biomassa seca em média, representando

TABELA 1 - Estimativas de biomassa aérea seca, em kg, para o fuste, galhos vivos e folhas para as seis árvores amostradas

Table 1 - Estimates of dry aboveground biomass, in $\mathrm{kg}$, for the bole, alive branches and leaves for the six sampled trees

\begin{tabular}{ccccc}
\hline \multirow{2}{*}{ Árvore $\mathrm{N}^{\circ}$} & \multicolumn{4}{c}{ Peso Seco em kg } \\
\cline { 2 - 5 } & Fuste & Galhos Vivos & Folhas & Total \\
\hline 1 & 14,11 & 2,97 & 1,04 & 18,12 \\
2 & 17,09 & 4,32 & 1,12 & 22,54 \\
3 & 18,95 & 3,95 & 1,29 & 24,19 \\
4 & 16,91 & 4,58 & 1,15 & 22,64 \\
5 & 18,06 & 4,30 & 0,97 & 23,34 \\
6 & 14,98 & 4,81 & 1,15 & 20,93 \\
\hline Média & 16,68 & 4,16 & 1,12 & 21,96 \\
$\%$ & 75,97 & 18,92 & 5,11 & 100,00 \\
\hline
\end{tabular}

$75,97 \%$ da biomassa seca total. As folhas e galhos vivos apresentaram em média 1,12 kg e 4,16 kg de biomassa seca, respectivamente, o que representa $24,03 \%$ da biomassa seca total. Não foi verificada a existência de galhos mortos nas árvores amostradas. A distribuição da biomassa aérea seca seguiu a ordem: fuste $>$ galhos vivos $>$ folhas $>$ galhos mortos.

Curlin (1970) afirmou que normalmente entre os compartimentos arbóreos, a produção de

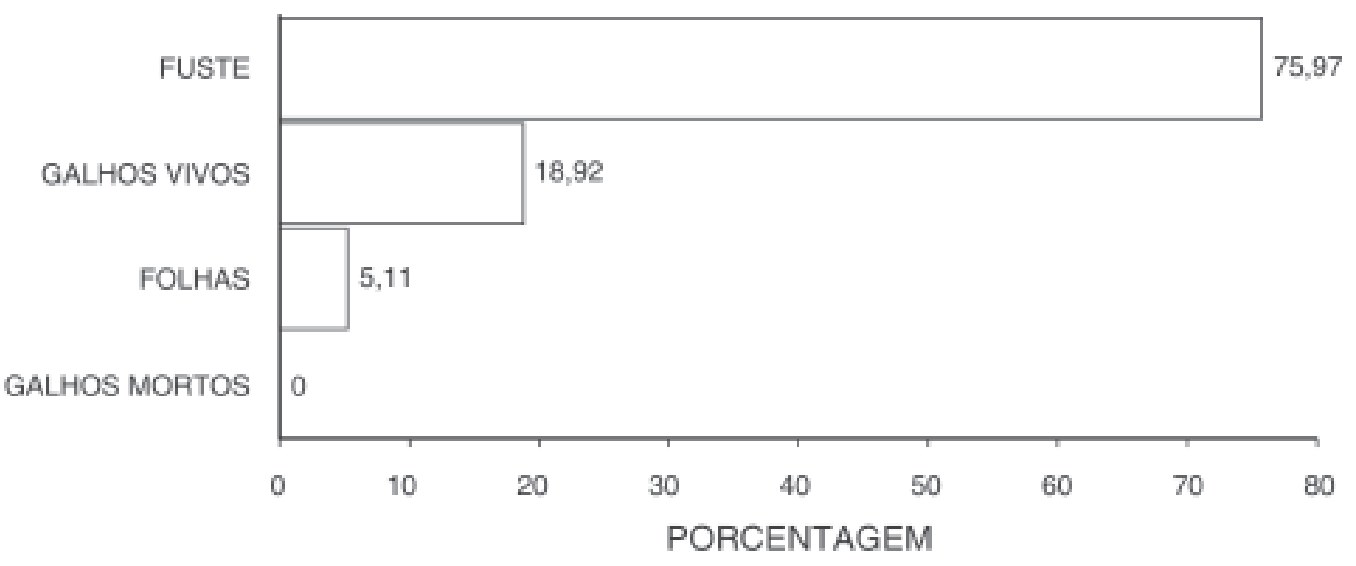

FIGURA 7 - Distribuição relativa dos componentes da biomassa aérea do craveiro, para seis árvores abatidas, em Tijucas do Sul, PR

Figure 7 - Relative distribution of the components of the craveiro aboveground biomass, for six cut trees, in Tijucas do Sul, PR 
biomassa seca obedece a ordem, lenho $>$ galhos $>$ casca $>$ folhas. Trabalhando em uma Floresta Ombrófila Mista Montana, em General Carneiro, Estado do Paraná, Watzlawick (2003) encontrou de $45,01 \%$ de biomassa seca nos galhos vivos, $50,52 \%$ no fuste com casca, 1,16\% nos galhos mortos, $2,40 \%$ nas folhas e $0,97 \%$ na porção denominada miscelânea.

A biomassa de folhas é componente importante no craveiro (Pimentapseudocaryophyllus), pois são delas que se extraem os óleos essenciais, sem a necessidade de se destruir as árvores. Para Sanchez (1976), de maneira geral, em média as folhas contribuem entre 4 a $6 \%$ da biomassa total. A biomassa de folhas estimada no presente trabalho encontra-se entre os valores encontrados por Watzlawick (2003), com 2,40\%, e Socher (2004), com 6,86\%, ainda que essa quantidade não represente somente a porção folhas.

\section{Rendimento do óleo essencial}

Os resultados obtidos para o rendimento de óleo essencial do craveiro (Pimentapseudocaryophyllus), calculados em base úmida e seca, estão apresentados na Tabela 2.

Considerando que o tempo de extração foi de 5 horas, os resultados obtidos para a

TABELA 2 - Resultados de densidades $\left(\mathrm{g} \mathrm{ml}^{-1}\right)$ e rendimentos absoluto e relativo do óleo essencial, em base seca $\left(\mathrm{mg} \mathrm{g}^{-1}\right)$, para as seis árvores amostradas

Table 2 - Results of densities $\left(g \mathrm{gl}^{1}\right)$ and absolute and relative yield of essential oil ( $\left.m g g^{-1}\right)$, referred to dry estimates, for the six sampled trees

\begin{tabular}{lccc}
\hline & \multicolumn{3}{c}{ RENDIMENTO } \\
\hline ÁRVORE & DENSIDADE $(\mathrm{g} \mathrm{ml}-1)$ & $\mu \mathrm{g} \cdot \mathrm{g}^{-1}$ & $\%$ \\
\hline 1 & 1,13025 & 29,23 & 2,92 \\
2 & 1,10996 & 25,14 & 2,51 \\
3 & 1,12684 & 30,22 & 3,02 \\
4 & 1,08982 & 24,30 & 2,43 \\
5 & 1,11422 & 25,40 & 2,54 \\
6 & 1,11422 & 24,17 & 2,42 \\
\hline MÉDIA & 1,11422 & 26,41 & 2,64 \\
DESVIO PADRÃO & 0,01853 & 2,63 & 0,26 \\
COEFICIENTE DE VARIAČÃO $\%$ & 1,66 & 9,96 & 9,96 \\
\hline
\end{tabular}

densidade revelaram uma amplitude de variação de 1,09 a $1,13 \mathrm{~g} \mathrm{ml}^{-1}$, com um coeficiente de variação de 1,66\%. Os rendimentos, em base seca, variaram de 24,17 a 30,22 $\mathrm{mg} \mathrm{g}^{-1}$. Os rendimentos em porcentagem apresentaram variação de 2,42 a 3,02\%. Lullez (1991) obteve um rendimento de óleo essencial para a mesma espécie na ordem de 1,00\%, com densidade 1,08 $\mathrm{g} \mathrm{ml}^{-1}$. Fenik (1972), com a espécie Pseudocaryophyllus guili (Spog), obteve um óleo com rendimento variando de 0,17 e 0,21\%, enquanto que CORREA (1979), com a espécie Pseudocaryophyllus pabstianus Legrand, obteve um óleo essencial com rendimento variando de 0,8 e 1,2\%. Craveiro (1981), com a espécie Pseudocaryophyllus jaccoudii Mattos, obteve um óleo essencial com rendimento de 2,0\%.

\section{Estimativas de produção óleo}

Foram identificadas 26 árvores de craveiro (Pimenta pseudocaryophyllus) nas três parcelas, de um hectare cada, integrantes da rede de parcelas permanentes do Projeto Ecológico de Longa Duração (PELD). Em cada parcela foram encontradas 16, 5 e 5 árvores da espécie, respectivamente. A obtenção da estimativa da altura comercial de cada árvore foi feita utilizando uma função hipsométrica ajustada para tanto. Essa função foi ajusta- 
da a partir dos dados obtidos na cubagem de 40 árvores, sendo que as alturas comerciais médias das classes de diâmetro foram usadas e correlacionadas com os pontos médios das classes. A razão para tal procedimento deveu-se à grande variação encontrada nos dados referentes às alturas e respectivos diâmetros a altura do peito. Observou-se, nos dados coletados para a cubagem, que no craveiro (Pimenta pseudocaryophyllus), a altura comercial decresce com o aumento do diâmetro, provavelmente refletindo o aumento da proporção da copa das árvores com a idade, o que causa grande influência nas estimativas de biomassa aérea e de folhas. Em que pese o baixo número de classes, e como decorrência disso, o baixo número de pares de valores usados no ajuste da equação, esta apresentou um coeficiente de determinação de 0,89 e um erro-padrão da estimativa de 5,16\%. A equação resultante é apresentada abaixo e a tendência da relação entre as variáveis é mostrada na Figura 8.

$$
\begin{aligned}
& \mathrm{hc}=13,017 \mathrm{~d}^{-0,5756} \\
& \mathrm{R}^{2}=0,89 \\
& \mathrm{~s}_{\mathrm{yx}} \%=5,16 \%
\end{aligned}
$$

onde:

$\mathrm{hc}=$ altura comercial $\mathrm{em} \mathrm{m}$;

$\mathrm{d}=$ diâmetro à altura do peito em $\mathrm{cm}$.

Uma vez estimada a altura comercial individual, e de posse dos valores dos diâmetros disponibilizados pelo projeto PELD para cada uma das árvores, foi estimada a biomassa seca da parte aérea e das folhas, cujos resultados são apresentados por parcela na Tabela 3 e por indivíduo na Tabela 4.

Conforme apresentado na Tabela 3, a média de biomassa seca da parte aérea para as três

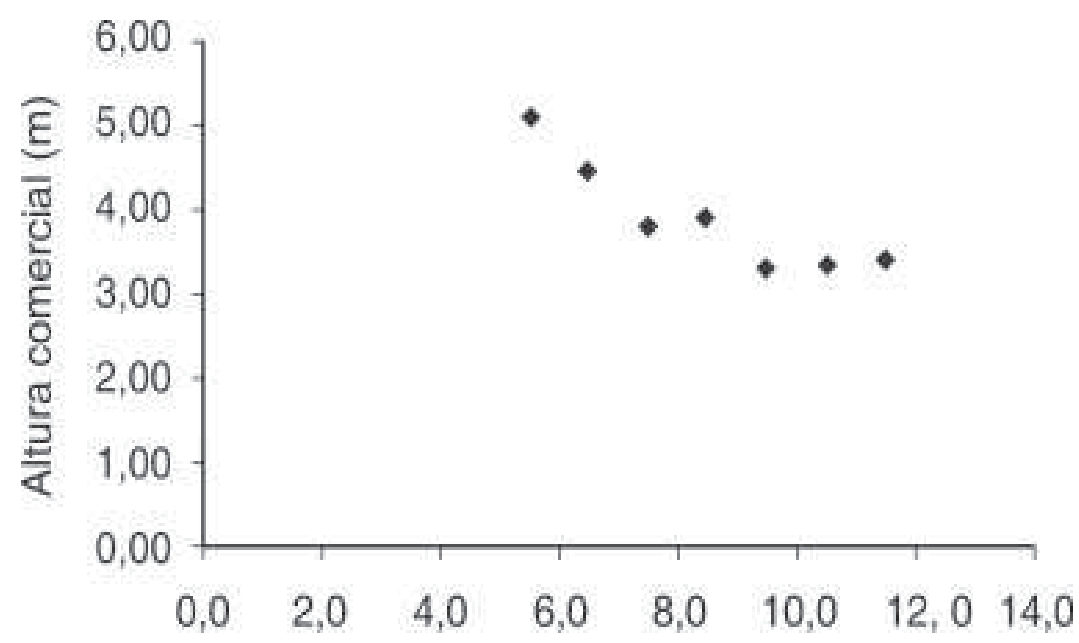

\section{Ponto médio da classe de diâmetro $(\mathrm{cm})$}

FIGURA 8 - Relação entre a altura comercial média por classes de diâmetro e o ponto médio da classe

Figure 8 - Relation between the average commercial height for diameter classes and the average point of the class 
TABELA 3 - Estimativas de biomassa seca da parte aérea e das folhas, em $\mathrm{kg} \mathrm{ha}^{-1}$, média por árvore, em kg, e do rendimento de óleo essencial em base seca, em $\mathrm{g} \mathrm{ha} \mathrm{a}^{-1}$, para as árvores de craveiro nas três parcelas do PELD - PUCPR

Table 3 - Estimates of dry biomass of the aboveground and leaves, in $\mathrm{kg} \mathrm{ha-1}$, average per tree, in $\mathrm{kg}$, and of the essential oil yield referred to dry base, $g \mathrm{ha}^{-1}$, for the trees of craveiro in the three plots of PELD - PUCPR

\begin{tabular}{lcccc}
\hline & \multicolumn{3}{c}{ Biomassa Seca } & Rendimento de \\
\cline { 2 - 4 } PARCELA & $\begin{array}{c}\text { Aérea } \\
\left(\mathrm{kg} \mathrm{ha}^{-1}\right)\end{array}$ & $\begin{array}{c}\text { Folhas } \\
\left(\mathrm{kg} \mathrm{ha}^{-1}\right)\end{array}$ & $\begin{array}{c}\text { Folhas Média } \\
\text { Árvore } \\
(\mathrm{kg})\end{array}$ & $\begin{array}{c}\text { Óleo Essencial } \\
\left(\mathrm{g} \mathrm{ha}^{-1}\right)\end{array}$ \\
\hline \multicolumn{1}{c}{1} & 816,96 & 31,07 & 1,94 & 820,26 \\
\multicolumn{1}{c}{1} & 180,32 & 7,22 & 1,44 & 190,52 \\
Total & 186,79 & 7,43 & 1,49 & 196,27 \\
Média & 1184,06 & 45,72 & 4,87 & 1207,04 \\
Desvio Padrão & 394,69 & 15,24 & 1,62 & 402,35 \\
Coeficiente de Variação \% & 365,71 & 13,71 & 0,28 & 361,93 \\
\hline
\end{tabular}

parcelas do projeto PELD foi de 394,7 $\mathrm{kg} \mathrm{ha}^{-1}$, de biomassa seca de folhas de $15,2 \mathrm{~kg} \mathrm{ha}^{-1}$ e por árvore de 1,6 kg. A média do rendimento de óleo essencial para as três parcelas foi de 402,4 $\mathrm{g} \mathrm{ha}^{-1}$. As diferenças na produção de biomassa seca e rendimento de óleo essencial entre as parcelas são devidas ao diferente número de indivíduos por parcela. As parcelas que apresentaram o mesmo número de árvores de craveiro (Pimenta psendocaryophyllus) mostraram resultados semelhantes para as variáveis analisadas.

Considerando individualmente as árvores de craveiro (Pimenta pseudocaryophyllus), foi obtida uma biomassa seca média da parte aérea de 45,5 kg, e uma média de 1,8 kg para as folhas. A biomassa seca da parte aérea apresentou um coeficiente de variação na ordem de $93,2 \%$, enquanto que para a biomassa das folhas o coeficiente de variação foi de $76,6 \%$. O rendimento médio de óleo essencial, em base seca, foi de 46,4 g. Os intervalos de confiança para as médias de biomassa seca da parte aérea, das folhas e do rendimento de óleo essencial, a $95 \%$ de probabilidade, são apresentados abaixo.

a) biomassa seca da parte aérea em kg:

$$
\mathrm{IC}=(28,39 \leq \mu \leq 62,69)=95 \%
$$

b) biomassa seca de folhas em $\mathrm{kg}$ :

$$
\mathrm{IC}=(1,21 \leq \mu \leq 2,30)=95 \%
$$

c) rendimento de óleo essencial em g:

$$
\text { IC }=(32,06 \leq \mu \leq 60,79)=95 \%
$$

Imaginando-se a hipótese de um cenário onde houvesse um plantio homogêneo de craveiro, no espaçamento 3 x 3 metros, poder-se-ia inferir que, com uma biomassa seca média de folhas de 1,62 kg por árvore e um rendimento na ordem de 2,64\%, obter-se-ia um rendimento de $47,0 \mathrm{~kg}$ de óleo essencial por hectare.

Comparações dos resultados obtidos com os de trabalhos similares são difíceis, em função da inexistência de trabalhos envolvendo biomassa individual de espécies nativas. Socher (2004) e Watzlawick (2003), entre outros, apresentam resultados para diferentes tipologias florestais, sem apresentarem, no entanto, valores para espécies nativas individuais em florestas naturais, que foi o caso do presente trabalho.

No que tange à produção de óleo essencial, Nakaoka et al. (1994), trabalhando com a mesma espécie, obtiveram rendimento de óleo essencial de 2,1\%, em base úmida. Campos Corrêa e Gotlieb (1970), estudando os componentes de Pseudocaryo- phyllus pabstianus Legran, obtiveram rendimen- tos que variaram entre $0,8 \%$ a $1,2 \%$. 
TABELA 4 - Resultados das estimativas de biomassa seca da parte aérea e das folhas, em kg, e do rendimento de óleo essencial em base seca, em g, para as árvores de craveiro em três parcelas do PELD-PUCPR

Table 4 - Results of the estimates of dry biomass of the aboveground and leves, in kog, and of the essential oil yield referred to dry base, in $g$, for the craveiro trees in the three PELD-PUCPR plots

\begin{tabular}{|c|c|c|c|c|}
\hline \multirow{2}{*}{ Parcela } & \multirow{2}{*}{ Árvore } & \multicolumn{2}{|c|}{ Biomassa Seca } & \multirow{2}{*}{$\begin{array}{l}\text { Rendimento Base } \\
\text { Seca (g) }\end{array}$} \\
\hline & & Aérea (kg) & Folhas (kg) & \\
\hline \multirow{16}{*}{1} & 1 & 29,10 & 1,24 & 32,76 \\
\hline & 2 & 25,97 & 1,16 & 30,60 \\
\hline & 3 & 33,06 & 1,35 & 35,71 \\
\hline & 4 & 81,92 & 2,87 & 75,81 \\
\hline & 5 & 186,02 & 6,23 & 164,57 \\
\hline & 6 & 25,60 & 1,15 & 30,36 \\
\hline & 7 & 181,43 & 6,08 & 160,62 \\
\hline & 8 & 29,10 & 1,24 & 32,76 \\
\hline & 9 & 34,34 & 1,39 & 36,69 \\
\hline & 10 & 33,06 & 1,35 & 35,71 \\
\hline & 11 & 27,65 & 1,20 & 31,73 \\
\hline & 12 & 25,97 & 1,16 & 30,60 \\
\hline & 13 & 27,65 & 1,20 & 31,73 \\
\hline & 14 & 25,24 & 1,14 & 30,13 \\
\hline & 15 & 25,60 & 1,15 & 30,36 \\
\hline & 16 & 25,24 & 1,14 & 30,13 \\
\hline Total & & 816,96 & 31,07 & 820,26 \\
\hline Média & & 51,06 & 1,94 & 51,27 \\
\hline Desvio Padrão & & 53,57 & 1,70 & 44,84 \\
\hline Coeficiente de Variação \% & & 104,91 & 87,47 & 87,47 \\
\hline \multirow[t]{5}{*}{ 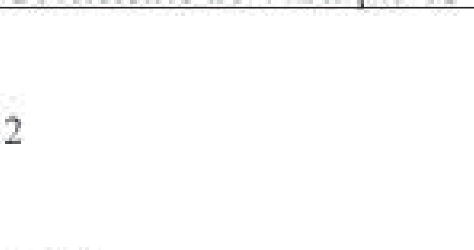 } & 17 & 28,60 & 1,23 & 32,40 \\
\hline & 18 & 38,59 & 1,52 & 40,02 \\
\hline & 19 & 43,44 & 1,66 & 43,89 \\
\hline & 20 & 37,84 & 1,49 & 39,43 \\
\hline & 21 & 31,84 & 1,32 & 34,79 \\
\hline Total & & 180,32 & 7,22 & 190,52 \\
\hline Média & & 36,06 & 1,44 & 38,10 \\
\hline Desvio Padrão & & 5,86 & 0,17 & 4,54 \\
\hline Coeficiente de Variação \% & & 16,25 & 11,92 & 11,92 \\
\hline \multirow{5}{*}{ ( } & 22 & 26,78 & 1,18 & 31,13 \\
\hline & 23 & 58,11 & 2,12 & 55,90 \\
\hline & 24 & 33,06 & 1,35 & 35,71 \\
\hline & 25 & 32,44 & 1,33 & 35,24 \\
\hline & 26 & 36,39 & 1,45 & 38,29 \\
\hline Total & & 186,79 & 7,43 & 196,27 \\
\hline Média & & 37,36 & 1,49 & 39,25 \\
\hline Desvio Padrão & & 12,10 & 0,37 & 9,65 \\
\hline Coeficiente de Variação \% & & 32,40 & 24,59 & 24,59 \\
\hline
\end{tabular}


Com base nos resultados obtidos, é possível concluir e recomendar para o craveiro (Pimenta psendocaryophyllus) que:

- o modelo proposto por Staote resultou em melhor ajuste para as estimativas de volume individual com casca, que apresentou estatísticas dentro de limites aceitáveis $\left(\mathrm{R}^{2}=0,90 \mathrm{e}\right.$ $\left.\mathrm{s}_{\mathrm{vx}}=10,2 \%\right)$;

- o modelo para estimativas de volume individual com casca deve ser utilizado com restrições, recomendando-se sua aplicação somente dentro da amplitude de diâmetros e alturas comerciais incluídos nessa pesquisa. O uso do modelo para outras situações e localizados em diferentes sítios, implica em seu teste prévio de precisão e acuidade;

- a biomassa seca aérea individual $(\mathrm{kg})$ seguiu uma ordem decrescente de produção (fuste $>$ galhos vivos > folhas;

- o modelo ajustado para obtenção de biomassa aérea seca individual, em kg, apresentou estatísticas de bom ajuste $\left(\mathrm{R}^{2}=0,97\right)$ e baixo erro-padrão da estimativa em porcentagem $(8,2 \%)$

- o modelo ajustado para a obtenção de estimativas da biomassa seca do fuste, em $\mathrm{kg}$, apresentou estatísticas de bom ajuste $(0,97)$ e erro-padrão da estimativa da ordem de $7,9 \%$;

- o modelo escolhido para a obtenção da biomassa seca de folhas, em kg, apresentou um coeficiente de determinação de 0,95 e um erro-padrão da estimativa de 10,1\%;

- o modelo de melhor ajuste para a obtenção de estimativas da biomassa seca dos galhos vivos, em $\mathrm{kg}$, apresentou $\mathrm{R}^{2}$ igual a 0,99 e 3,14\% para o erro-padrão da estimativa; e

- o rendimento porcentual da produção de óleo essencial foi de $2,64 \%$, em base seca, com um coeficiente de variação na ordem de $10 \%$;

Dado o alto rendimento na produção de óleo essencial a partir das folhas, sugere-se um manejo florestal em que seja implantado um sistema de poda das folhas que proporcione a regeneração foliar, sem danos ecológicos ao bioma onde a espécie se encontra.

\section{REFERÊNCIAS}

CAMPOS CORRÊA, R. G.; GOTTLIEB, O. R. Óleo essencial da Mirtácea Pseudocaryopyllus pabstianus. Manaus: Instituto Nacional de Pesquisas da Amazônia, v. 11, p. 1-5, 1970.

CORREA, R. G. et al. Óleos essenciais de espécies do gênero Pseudocaryophyllus. In: CONGRESSO INTERNACIONAL DE ÓLEOS ESSENCIAIS. 5, 1971, Rio de Janeiro. Anais... Academia Brasileira de Ciências. Rio de Janeiro, v. 44, p. 307-309, 1979.

CRAVEIRO, A. A. et al. Óleos essenciais de plantas do nordeste. Fortaleza: Universidade Federal do Ceará, 1981. p. 209.

CURLIN, J. W. Nutrient cycling as a factor in site productive and forest fertilization. In: YOUNGBERG, C. T.; DAVEY T. (Ed.). Tree growth and forest soils. Oregon: Oregon State University Press, 1970. p. 313-326.

FENIK, I. J. S.; RETAMAR, J. A. El aceite assencial de Pseudocaryophyllus guili. In: CONGRESSO INTERNACIONAL DE ÓLEOS ESSENCIAIS. 5, 1972, Rio de Janeiro. Anais... Academia Brasileira de Ciências. Rio de Janeiro, v. 44, 1972. p. 175-180.

GOTTLIEB, O. R.; MORS, W. B. Potential interligation of Brazilian wood extractives. Journal of Agricultural and Food. Chemestry, v. 28, p. 196-215, 1980. 
LULLEZ, J. C. Identificação de metileugenol, eugenol e chavibetol no óleo essencial da folha de Psendocaryophyllus acuminatus (Limk) Burret. Curitiba. 1991. 124 f. Dissertação (Mestrado em Engenharia Química) - Universidade Federal do Paraná, Curitiba, 1991.

MAACK, R. Geografia física do Estado do Paraná. Curitiba: CODEPAR, 1968.

NAKAOKA, S. M et al. Óleo essencial de pimenta Pseudocaryophyllus var. pseudocaryophllus (Gomes) ladrum (myrtacear) I: cromatografia a gás / espectro metria de massa (cg/em). Revista do Instituto Florestal, São Paulo, v. 6 (único).

PATON, P. S. Estimativa de volumes individuais expressos em metros cúbicos sólido e estéreos, para bracatinga Mimosa scabrella Benth em povoamentos naturais maduros. Curitiba. 1984. Dissertação, 107 f. (Mestrado em Engenharia Florestal) - Setor de Ciências Agrárias, Universidade Federal do Paraná, Curitiba, 1984.

SANCHEZ, P. A. Properties and management of soils in the tropics. New York: John Wiley and Sons, 1976.

SOCHER, L. G. Dinâmica e biomassa aérea de um trecho de floresta Ombrófila mista aluvial no município de Araucária, Paraná. Curitiba. 2004. 87 f. Dissertação (Mestrado em Engenharia Florestal) - Setor de Ciências Agrárias, Universidade Federal do Paraná, Curitiba, 2004.

WATZLAWICK, L. F. Estimativa de biomassa e carbono em floresta ombrófila mista e plantações florestais a partir de dados de imagens do satélite IKONOS II. Curitiba. 2003. Tese, 119 f. (Doutorado em Engenharia Florestal) - Setor de Ciências Agrárias, Universidade Federal do Paraná, Curitiba, 2003.

Recebido em: 14/05/2006

Received in: 05/14/2006

Aprovado em: 30/09/2006 Accepted in: 09/30/2006 